\title{
FRACTURE STRENGTH AND MICROLEAKAGE OF SIMULATED IMMATURE TEETH REINFORCED WITH FIBER POST: IN VITRO STUDY
}

\author{
Mohamed S Mohamed ${ }^{*}$, Cherif A Mohsen ${ }^{* *}$ and Mohamed M Metwally***
}

\begin{abstract}
Aim of the study: This in vitro study was conducted to investigate the fracture strength and microleakage of simulated immature teeth reinforced with fiber post using two types of composite resin cement " total etch and self etch ".

Materials and methods: Eighty freshly extracted maxillary central incisors were used in the study, they were divided into two groups (40 samples for each) according to the stage of root development (mature - immature), Then each group was subdivided into two subgroups (20 samples for each) according to the type of adhesive composite resin cement (RELY X TM U200 Automix) (3M ESPE Germany) self-adhesive and (Bifix QM) ( Voco. GERMANY) total etch , Each subgroup was further divided into two classes (10 samples for each) according to subjecting the samples to thermocycling or not, Finally 5 samples from each class were tested for fracture strength by using universal testing machine and the other 5 samples of each class were tested for microleakage by using digital microscope.
\end{abstract}

Results: The results of the fracture strength test showed that mature teeth showed higher fracture strength than simulated immature teeth. Total etch composite resin composite cement showed higher fracture strength than self etch cement. Finally the results showed that thermocycling affects negatively on fracture strength. As regard microleakage, the reults pointed out that no microleakage occurred in all tested groups.

Conclusions: Fracture strength of mature teeth is more than immature teeth, using total etch composite resin cement give more fracture strength than self etch composite resin cement, thermocycling affects negatively the fracture strength for mature or immature endodontically treated teeth, no microleakage occurred irrespective to the state of restored root (mature or immature).

KEY WORDS: Simulated immature, total etch, self etch, fiber post, fracture strength, microleakage.

* Candidate in Crown and Bridge Department, Faculty of Dentistry, Minia University.

** Prof. and Chairman of Crown and Bridge Department, Faculty of Dentistry, Minia University

*** Lecturer of Crown and Bridge, Crown and Bridge Department, Faculty of Dentistry, Minia University 


\section{INTRODUCTION}

Restoration of an endodontically-treated tooth with extensive coronal destruction requires a post-and-core restoration to retain full and final crown restoration, In the anterior esthetic zone, a translucent fiber post may be a better choice if the tooth is being restored with translucent, esthetic restorative materials ,composite resin, porcelain veneers, or an all-ceramic crown ${ }^{(1)}$.

Fiber-reinforced posts (FRPs) bonded to intraradicular dentin ${ }^{(2)}$ using adhesive systems are preferred by many clinicians, as they are easier and faster to fabricate and less expensive than custommade post and cores. Favorable stress distribution of FRPs along the root that prevents catastrophic root fractures has been attributed to their modulus of elasticity being similar to dentin ${ }^{(3)}$.

The fracture resistance of a post and core-restored tooth is proportional to the residual dentin tissue, as decreased root dentin thickness will weaken the tooth/dowel complex.

Although a decrease in microleakage in teeth restored with bonded FRPs compared with teeth restored with non-dentin bonding luting agents has been reported, leakage along the dowel space remains a concern.

\section{MATERIALS AND METHODS}

\section{Teeth selection, cleaning, storage and preparation}

Eighty freshly extracted maxillary central incisors were used in the study. For disinfection purpose, teeth were immersed in $5.25 \%$ sodium hypochlorite solution for 24 hours. Hard and soft tissue deposits were then removed using ultrasonic instrumentation (Cavitron; Dentsply Intl, York, Pa). Thereafter, they were stored in saline.

Eighty tooth were studied; they were divided into two groups (40 samples for each) according to the stage of root development (mature immature), Then each group was subdivided into two subgroups (20 samples for each) according to the type of adhesive composite resin cement. Each subgroup was further divided into two classes (10 samples for each) according to subjecting the samples to thermocycling or not.Finally 5 samples from each class were tested for fracture strength and the other 5 samples of each class were tested for microleakage.

Equal length of sound tooth structure from the root apex to the sectioned surface were measured and marked with a pencil on the selected teeth. These latter were sectioned using a diamond rotary cutting instrument (760 R; Kerr Dental, Orange, Calif, USA).This created a planned sectioned surface perpendicular to the long axis of the tooth. The remaining root length was $12 \pm 0.5$. Materials used in this study are listed in table 1.

\begin{tabular}{|c|c|c|}
\hline Types & $\begin{array}{c}\text { Commercial } \\
\text { names }\end{array}$ & Manufactures \\
\hline $\begin{array}{c}\text { Prefabricated } \\
\text { fiber post }\end{array}$ & Rely X fiber post & $\begin{array}{c}\text { 3M ESPE. Seefeld } \\
\bullet \text { GERMANY }\end{array}$ \\
\hline $\begin{array}{c}\text { Self etch adhesive } \\
\text { composite resin } \\
\text { cement }\end{array}$ & $\begin{array}{c}\text { Rely X U200 } \\
\text { Automix }\end{array}$ & $\begin{array}{c}\text { 3M ESPE. Seefeld } \\
\bullet \text { GERMANY }\end{array}$ \\
\hline $\begin{array}{c}\text { Total etch } \\
\text { adhesive } \\
\text { composite resin } \\
\text { cement }\end{array}$ & Bifix QM & Voco. GERMANY \\
\hline $\begin{array}{c}\text { Obturating } \\
\text { material (MTA) }\end{array}$ & Angelus & PR,BRAZIL \\
\hline
\end{tabular}

\section{Root canal treatment and obturation}

\section{Control group (mature teeth)}

Root canal preparation was performed using $\mathrm{Ni}$ Ti rotary system (Protaper, DENTSPLY, Tulsa, USA) according to the manufacturer's recommendations.

Alternative irrigation with sodium hypochlorite $(\mathrm{NaOCl})$ solution5.25\% and ethylene diamine tetra acetic acid (EDTA) was performed.

A sealer (Ah 26; Dentsply Tulsa, USA) was mixed according to manufacturer's instruction 
and introduced into the canal using paper points. Teeth were obturated with 0.04 taper ISO No. 40 gutta percha cones (Lexicon; Dentsply Tulsa,USA) using lateral condensation technique. A periapical radiograph was taken to assess the accuracy of obturation.

\section{Simulated immature teeth}

Peeso reamers between \#1 and \#6 were introduced in the root canals and a \#6 Peeso reamer was allowed to protrude $1 \mathrm{~mm}$ beyond the apex. The remaining dentin thickness 1-2 $\mathrm{mm}$. The root canals were irrigated using $2 \mathrm{ml}$ of $5.25 \%$ sodium hypochlorite after each file and a final flush with $5 \mathrm{ml}$ of $17 \%$ EDTA was made to remove the smear layer. Finally, the root canals were flushed with distilled water and dried using paper points (Lexicon; Dentsply Tulsa).

To simulate clinical conditions, a calcium hydroxide paste was introduced in the root canals. Then, the root canal accesses were filled using a temporary filling material (Cavit; 3M ESPE, St Paul, MN, USA.) and the samples were kept for 7 days at 370C under $100 \%$ humidity.

Following the 7-day incubation period, the temporary filling material was removed from the access cavities, and the previously placed calcium hydroxide paste was removed from the root canals using $5.25 \%$ sodium hypochlorite and a final flush with $17 \%$ EDTA. A final irrigation was made using distilled water and the root canals were dried with paper points.

\section{MTA application}

White ProRoot MTA (Angelus) was prepared according to the manufacturer's instructions and placed in the root canal using a lentulo spiral until 2 mm short of the apex ${ }^{(4)}$. A cotton pellet moistened with distilled water was wrapped around a file and the MTA was condensed until a 4- to 5-mm apical thickness was achieved. The thickness and homogeneity of the MTA plug were radiographic confirmed. The apices of the experimental teeth were covered with a wet cotton pellet and the samples were kept for $12 \mathrm{~h}$ at $37^{\circ} \mathrm{C}$ under $100 \%$ humidity for allowing MTA to set completely.

\section{Mold preparation}

An acrylic resin blocks was made to properly fix each root in an exact vertical direction. The following steps were performed:

A- Construction of the split Copper mold.

B- Adjusting the root in the proper axial direction.

C- Root blocks formation.

\section{Post space preparation}

Post space preparation for all teeth was initiated after obturation. The post room was prepared by using an axio drill. It is composed of a lower aluminum base to which a steel vertical rod is fixed. An attached stand is connected to the vertical rod to which a straight hand piece is mounted; $90^{\circ}$ angled and securely fixed to it. The stand is allowed to move up and down in an exact vertical direction by means of a fixed horizontal arm through a spring. The straight hand piece is connected to a low speed motor (15.000-rpm). This design permits the creation of an exact vertically drilled post-hole. A post drill (size 1 refill pack RelyX fiber post drill.3M ESPE. GERMANY) was used to prepare the post spaces at a speed of $5000 \mathrm{rpm}$. The created depth was $9 \mathrm{~mm}$. This was to ensure that $5 \mathrm{~mm}$ gutta-percha apical was left.

\section{Post cementation}

Half of samples of control group and simulated immature teeth were cemented using self etch adhesive composite resin cement (RELY X TM U200 Automix, 3M ESPE. Seefeld • GERMANY) and the another half were cemented using total etch adhesive composite resin cement (Bifix QM, Voco. GERMANY) according manufacture instructions. 


\section{Thermocycling}

Prior to testing, half of samples in each subgroup were stored in distilled water at $370 \mathrm{C}$ for 2 days and all of them were additionally subjected to thermocycling between water temperatures of $5^{\circ} \mathrm{C}$ and $55^{\circ} \mathrm{C}$ with a dwell time of 20 seconds for 3000 cycles, using an automated thermal cycling machine. One thousand cycles represent two years of clinical survival which is described in ISO/TS 11405 were performed.

\section{Fracture strength test}

The specimens were stored in $100 \%$ humidity at $37{ }^{\circ} \mathrm{C}$ until fracture testing using universal testing machine. For the fracture testing, a jig was prepared that allowed the fixation of the cylinders at an angle of 450. A compressive load was applied at a crosshead speed of $1 \mathrm{~mm}$ min until fracture. Loading was adjusted so that the force was applied from the palatal surface at a point corresponding to the middle of the mesio-distal length of the sectioned surface. The maximum load at which the specimens fractured was recorded in Newtons.

\section{Microleakage test}

The specimens were stored in tap water for one week at $37^{\circ} \mathrm{C}$ before being treated with a dye penetration test. The specimens were dried with air and were coated with clear nail varnish to prevent the dye from penetrating into the tooth. Areas $1 \mathrm{~mm}$ from the apical were left uncoated. The specimens were subsequently immersed in freshly prepared $2 \%$ methylene-blue solution in separate containers for one week. The specimens were then rinsed under running tap water, and any visual dye remnants on the surface were cleaned with a brush and pumice stone.Then the specimens were sectioned vertically into two sections by using IsoMet 4000 microsaw (buehler Germany precision cutting, Germany).All samples were positioned perpendicularly in a digitalmicroscope (Scope Capture Digital Microscope, Guangdong, China), magnification X25, and the images were captured and transferred to a IBM personal computer equipped with the Image-tool software (Image J 1.43U, National Institute of Health, USA(.Within the Image $\mathrm{J}$ software, all limits, sizes, frames and measured parameters are expressed in pixels. Therefore, system calibration was done to convert the pixels into absolute real world units. Calibration was made by comparing an object of known size (a ruler in this study) with a scale generated by the Image $J$ software. Then, the images of traced dye penetration path were overlaid and transferred to Image $\mathbf{J}$ software in order to calculate penetration depth measured in ( $\mathrm{mm})$.

\section{Statical analysis test}

All data were collected, means \& standard deviations were calculated $\&$ then statical analysis using ANOVA test and Multiple Comparisons Dependent Variable: VAR00002 LSD.

\section{RESULTS}

\section{Fracture strength test}

\section{1- Fracture strength of simulated immature teeth and mature teeth:}

The results showed that there is a statistical significant difference between the two groups. Mature teeth recorded higher fracture strength $(316.9235 \mathrm{~N})$ than simulated immature teeth $(269.5423 \mathrm{~N})$.

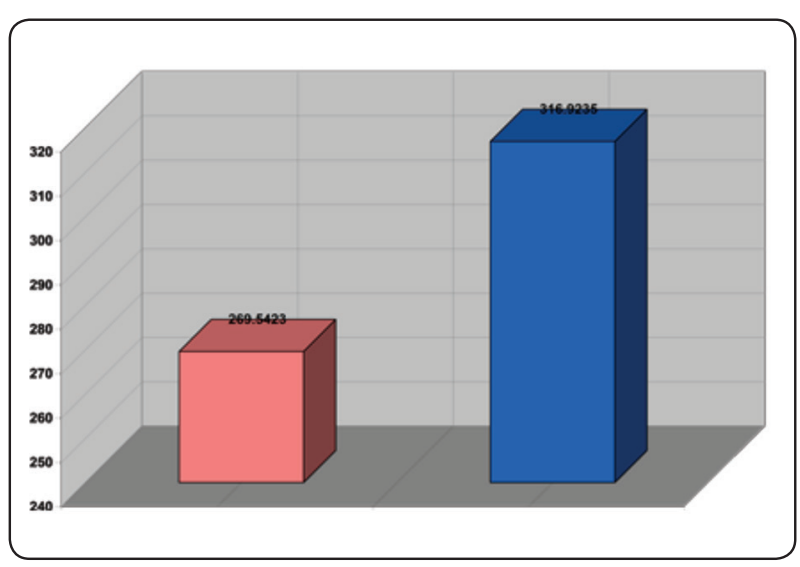

Fig. (1) Comparison between fracture strength of simulated immature teeth and mature teeth. 


\section{2- Fracture strength of mature teeth undergone thermocycling and mature teeth with no thermocycling:}

The results showed that there is a statistical significant difference between the two groups. Mature teeth with no thermocycling recorded higher fracture strength $(360.0310 \mathrm{~N})$ than those undergone thermocycling teeth $(273.8160 \mathrm{~N})$.

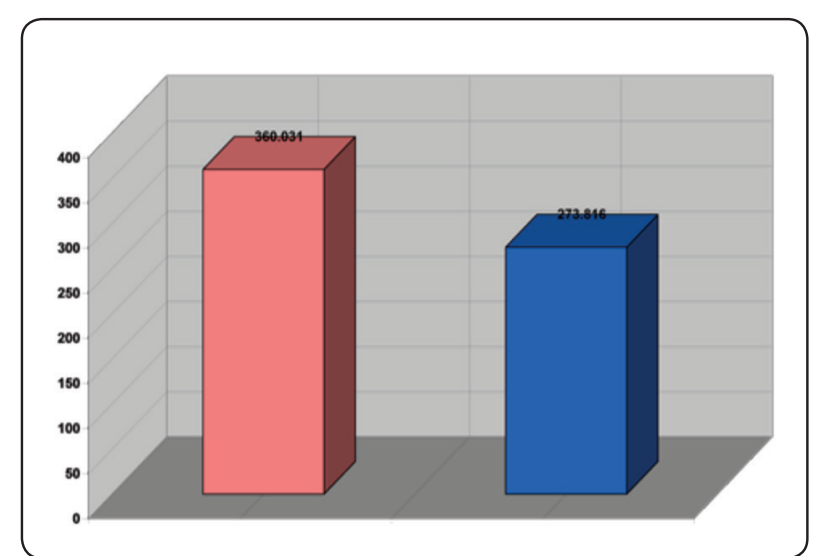

Fig. (2) Comparison between fracture strength of mature teeth undergone thermocycling and mature teeth with no thermocycling.

\section{3- Fracture strength of simulated immature teeth undergone thermocycling and immature teeth with no thermocycling:}

The results showed that there is a statistical significant difference between the two groups. Immature teeth with no thermocycling recorded higher fracture strength $(299.2557 \mathrm{~N})$ than those undergone thermocycling teeth $(239.8290 \mathrm{~N})$.

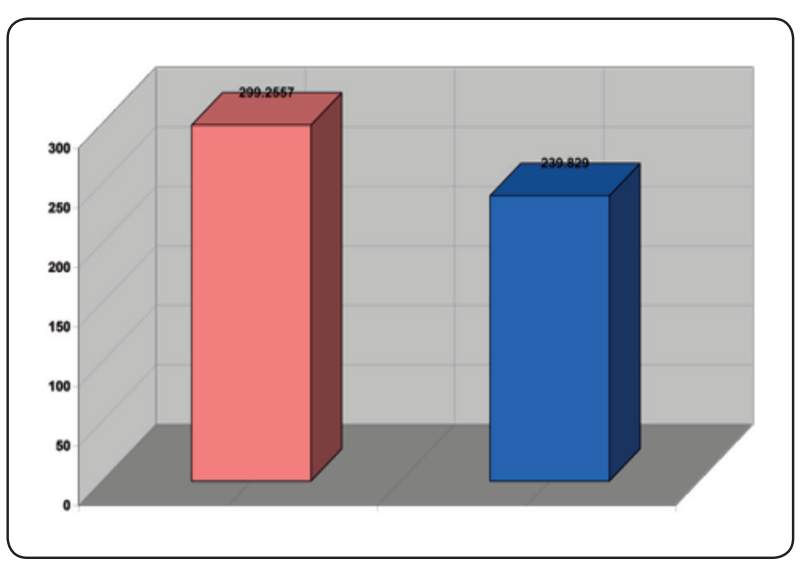

Fig. (3) Comparison between fracture strength of simulated immature teeth undergone thermocycling and simulated immature teeth with no thermocycling.
4- Fracture strength of mature teeth undergone thermocycling restored with fiber post cemented with self etch composite resin cement and with total etch composite resin cement:

The results showed that there is a statistical significant difference between the two groups. Mature teeth undergone thermocycling restored with fiber post cemented with total etch composite resin cement recorded higher fracture strength $(291.7860 \mathrm{~N})$ than those undergone thermocycling and restored withe fiber post cemented with self etch composite resin cement $(255.8460 \mathrm{~N})$.

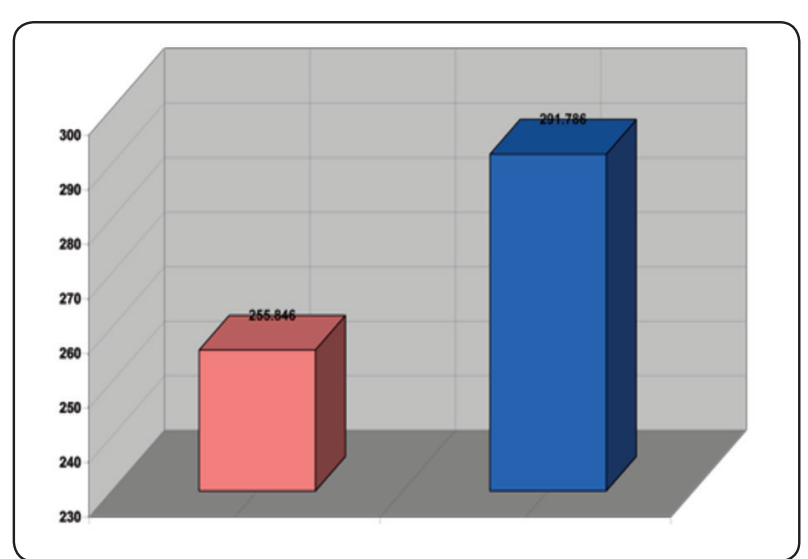

Fig. (4) Comparison between fracture strength of mature teeth undergone thermocycling restored with fiber post cemented with self etch composite resin cement and mature teeth and with total etch composite resin cement

\section{5- Fracture strength of simulated immature teeth} undergone thermocycling restored with fiber post cemented with self etch composite resin cement and with total etch composite resin cement:

The results showed that there is a statistical significant difference between the two groups. Simulated immature teeth undergone thermocycling and post cemented with total etch composite resin cement recorded higher fracture strength $(282.8700 \mathrm{~N})$ than those undergone thermocycling teeth restored with fiber post cemented with self etch composite resin cement $(196.7880 \mathrm{~N})$. 


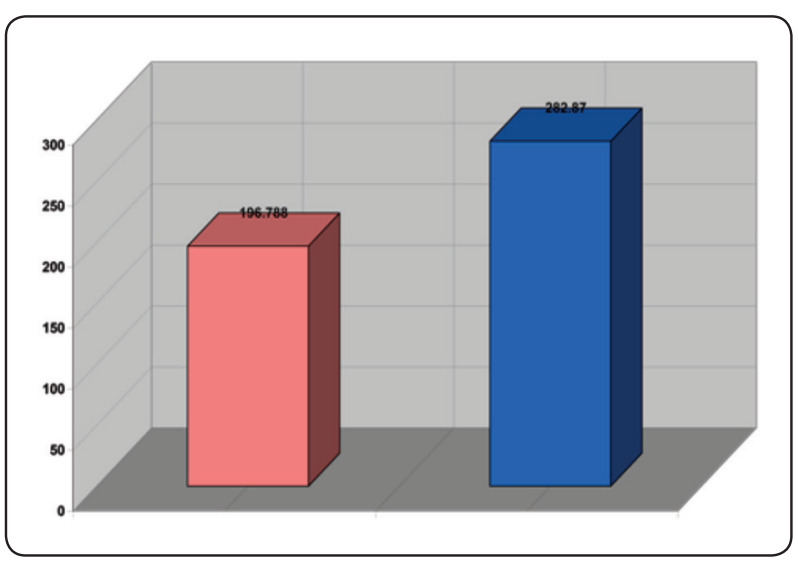

Fig. (5) Comparison between fracture strength of simulated immature teeth undergone thermocycling restored with fiber post cemented with self-etch composite resin cement and with total etch composite resin cement.

\section{6- Fracture strength of mature teeth with no ther-} mocycling restored with fiber post cemented with self etch composite resin cement and with total etch composite resin cement:

The results showed that there is a statistical significant difference between the two groups. Mature teeth with no thermocycling restored with fiber post cemented with total etch composite resin cement recorded higher fracture strength $(420.7660 \mathrm{~N})$ than those undergone thermocycling teeth restored with fiber post cemented with self etch composite resin cement $(299.2960 \mathrm{~N})$.

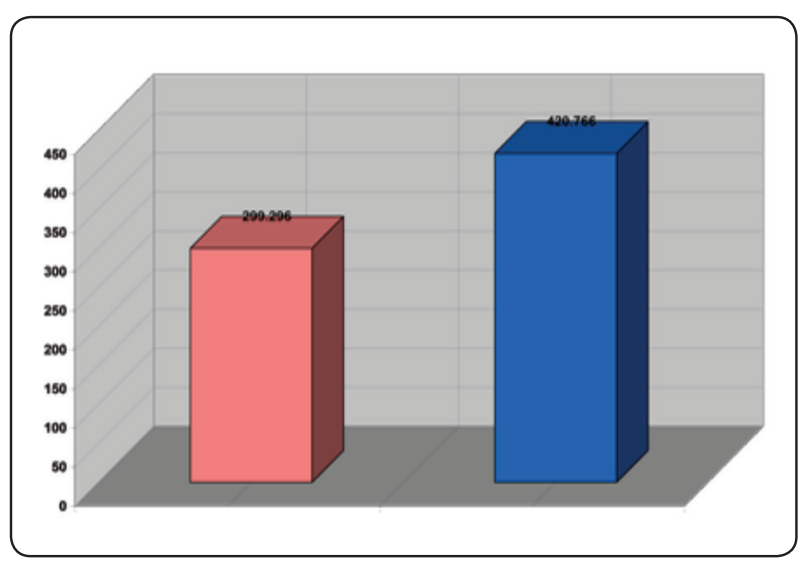

Fig. (6) Comparison between fracture strength of mature teeth with no thermocycling restored with fiber post cemented with self-etch composite resin cement and with total etch composite resin cement.

\section{7- Fracture strength of simulated immature teeth} with no thermocycling restored with fiber post cemented with self etch composite resin cement and with total etch composite resin cement:

The results showed that there is a statistical significant difference between the two groups. Simulated immature teeth with no thermocycling restored with fiber post cemented with total etch composite resin cement recorded higher fracture strength $(333.0554 \mathrm{~N})$ than those with no thermocycling restored with fiber post cemented with self etch composite resin cement $(265.4560 \mathrm{~N})$.

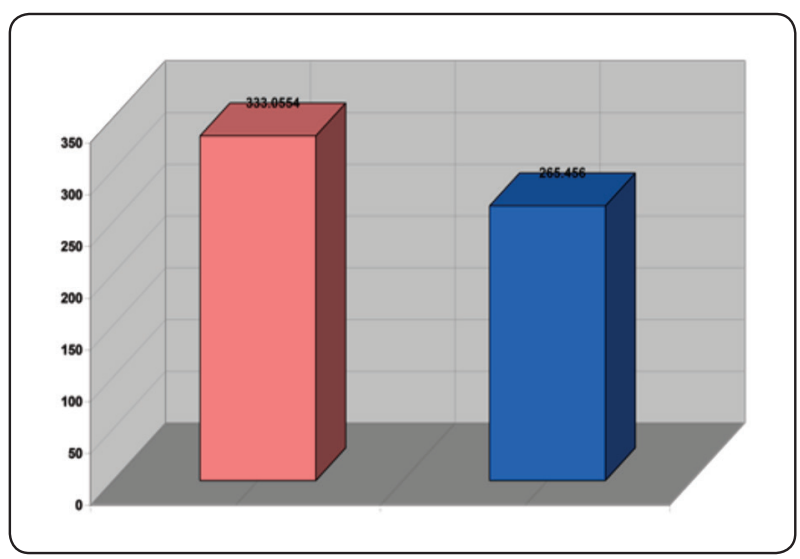

Fig. (7) Comparison between fracture strength of simulated immature teeth with no thermocycling restored with fiber post cemented with self-etch composite resin cement and with total etch composite resin cement.

\section{8- Fracture strength of all tested groups}

Means \& standard deviations of the fracture strength of all tested groups are shown in figure. The results showed that there is a statistical significant difference between all tested groups.

\section{Microleakage test}

All tested groups (mature or immature teeth) showed that no microleakage has been occurred. 


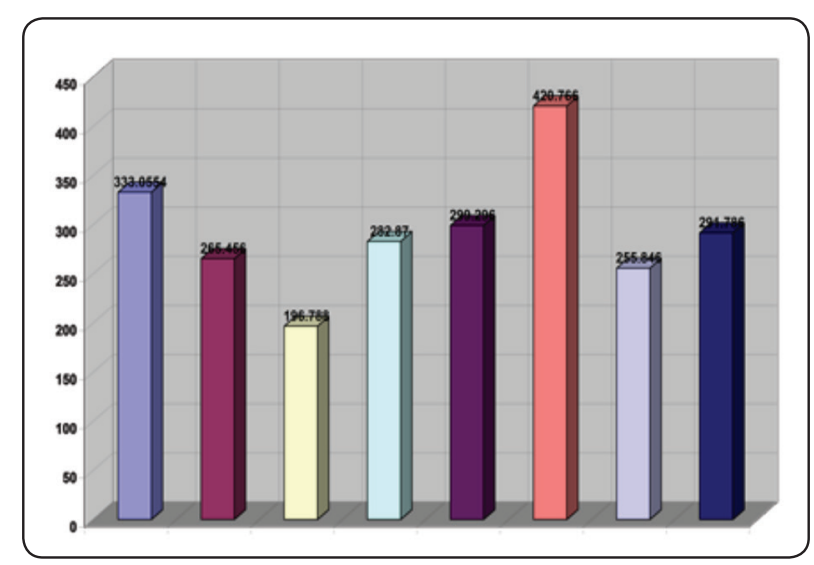

Fig. (8) Statistical difference between all tested groups.

\section{DISCUSSION}

This study was conducted to investigate the fracture resistance and micro leakage of simulated immature teeth using two types of composite resin cements (self etch and total etch). Since anterior teeth are more prone to trauma. It has been reported that prevalence of trauma involving upper central incisors is about $37 \%{ }^{(5)}$. The fracture of anterior teeth, especially if it involves extensive loss of tooth structure has a great psychological impact.

To prepare the mature group, 40 human maxillary central incisors free of any defects were selected. Crowns were transversely sectioned at the cement-enamel junction. Thereafter, the roots were endodontically treated.

Since the smear layer contains organic and inorganic matter ${ }^{(6)}$, that might be infected ${ }^{(7)}$ and its removal is proposed. Such practice may enhance the micromechanical retention when cementation of the post is done with resin cement ${ }^{(8)}$. As a result, $\mathrm{NaOCl}$ and EDTA were alternately used to remove the organic matrix and the inorganic material of the dentine substrate thus reducing the dentine microhardness ${ }^{(9)}$. Accordingly, a resin root canal sealer was used due to lesser amount of leakage and high tensile strength ${ }^{(4,10)}$. Studies reported more apical leakage after delayed post space preparation compared with immediate preparation ${ }^{(11,12)}$. Accordingly, post space preparation was initiated immediately after root canal treatment.
Mechanical method using gates-Glidden burs had been used. Mechanical removal of the coronal portion of root canal fillings can affect the quality of the seal of the root canal filling ${ }^{(13-15)}$, this method is preferred over the thermal one by many authors in terms of leakage ${ }^{(16-18)}$.

Viewing post space preparation, five $\mathrm{mm}$ remaining root canal filling was left in place to provide an adequate apical seal ${ }^{(19-22)}$. As an apical seal less than $5 \mathrm{~mm}$ is more prone to leakage which could not provide an adequate seal $(23,24)$.

In order to simulate immature teeth, another forty maxillary incisor teeth were selected. When mature teeth are enlarged to resemble immature teeth, the outer part of their roots would demonstrate lower tubular density and more intertubular dentine (25). It has therefore been concluded that although teeth used in these studies may morphologically mimic immature teeth, they are unable to do so in terms of tissue composition or physical characteristics ${ }^{(4)}$.

Prior to placement of MTA for apexification, the manufacturer recommends that the canal be medicated with calcium hydroxide for 1 week, with subsequent removal using sodium hypochlorite and instruments as needed. It has been indicated that this may enhance the difficult task of debriding the canal system with an open apex ${ }^{(26)}$.

MTA Fillapex has been developed very recently to be used as a permanent root canal filling material, presumably in an attempt to integrate the beneficial properties of mineral trioxide aggregate in a permanent sealing material. The possible advantages of this system are the utilization of the material with the desired gutta-percha techniques and the chance of removal, on the other hand, whether it exerts the same beneficial effects as the original MTA, such as calcium release and induction of cementogenesis, is a topic of discussion and needs to be supported by future studies ${ }^{(27)}$. Although the MTA-based sealer used in the present study was not evaluated in terms of these properties. MTA Fillapex can be considered as an a alternative root filling material 
and its usage in combination with an apical plug of MTA may provide the advantage of using materials of the same characteristics in the root canal system.

Fiber posts were chosen since they are designed to have physical properties similar to those of dentine. Moreover, they have a lower modulus of elasticity compared with metallic posts. Fiber post flexes slightly under load and distributes stresses to the root dentine, which is claimed to help reduce the incidence of root fracture ${ }^{(28)}$. When fracture occurs, the fiber post inside tends to fracture preferentially and the remaining root could be re-restored ${ }^{(29)}$.

Resin cementation eliminates the wedging effect of the post and reduces the susceptibility root to fracture $^{(30)}$. Bond strengths to root canal dentine are material dependent ${ }^{(31)}$. Two types of composite resin cement was (self etch and total etch) used as it is less soluble and more retentive when compared with other cements such as glass-ionomer and polycarboxylate cements ${ }^{(32,33)}$. Although resinmodified glass ionomer possesses higher bond strength than resin cement ${ }^{(34)}$, resin cement was used due to its higher fracture toughness ${ }^{(35)}$.

Thermal cycling is used to test the durability of resin bonds. It is considered to be clinically relevant aging parameters ${ }^{(36)}$ One thousand cycles represent two years of clinical survival which is described in ISO/TS $11405^{(37)}$.

Fracture strength is dependent on the modulus of elasticity of the material. Thus, it is considered a more meaningful property compared to compressive strength when validating materials suitability for structural components ${ }^{(38,39)}$. For the fracture testing, a jig as described by de Melo et al. ${ }^{(40)}$ was prepared that allowed the fixation of the cylinders at an angle of 45 . The effect of the periodontium was not reproduced in the present study and direct embedding in acrylic was preferred instead. It has been reported that covering roots with silicone or wax prior to embedding into acrylic might cause root movement during loading which may not exactly reflect clinical conditions. Also, it has been stated that the dissimilar elasticity of simulating materials from the periodontium are under representative of clinical status ${ }^{(41)}$ for the above mentioned reasons, the samples were directly embedded into acrylic and a more uniform dispersion of stress and reflection of clinical circumstances were anticipated by such an approach.

Using dye penetration method in testing microleakage has many advantages over the other techniques. First of all, microleakage is demonstrated by single colored agent without the need for any further introduction of chemical reaction or hazardous radiation. In addition the researchers can have a range of available dye agents, which allow the method to be easily confirmed and easily repeated. They can, to some extent, have clinical significance since the particle size of dye agents can be premeasured ${ }^{(42)}$.

The result showed that there is a statistical significant difference between the simulated immature teeth and mature teeth. Mature teeth recorded higher fracture strength $(316.9235 \mathrm{~N})$ than simulated immature teeth $(269.5423 \mathrm{~N})$. This is in accordance with Tanalp et al (2012) ${ }^{(45)}$ who reported that immature teeth exhibited low fracture resistance. This may be due to the fact that MTA placed apically does not exert a reinforcing effect ${ }^{(43)}$.

The results showed that there is a statistical significant difference between the mature \& immature teeth undergone thermocycling and those not subjected to thermocycling. Teeth undergone thermocycling recorded lower fracture strength $(273.8160 \mathrm{~N}$ for mature teeth, $239.8290 \mathrm{~N}$ for immature teeth) than those undergone thermocycling teeth $(360.0310 \mathrm{~N}$ for mature teeth, $299.2557 \mathrm{~N}$ for immature teeth). This may be due to the fact that strength is affected by thermocycling, as reported by Luthy et al (2006) ${ }^{(44)}$.

The results showed that there is a statistical significant difference between fracture strength of tested samples bonded with self-etch composite resin cement and those bonded with total etch composite resin cement irrespective to the state of tooth development or thermocycling. Teeth with 
total etch recorded higher fracture strength than self-etch. This may be due to the fact that the resinroot dentin interdiffusion zone is less pronounced with the self etching approach than with the total etch approach ${ }^{(45)}$.

The result showed that no significant microleakage occurred irrespective to the state of restored root (mature or immature). This may be due to the fact that MTA was used in this study. MTA is a recently developed promising material consisting of tricalcium oxide and other mineral oxides such as tricalcium silicate, silicate oxide, and tricalcium oxide. The $\mathrm{pH}$ of the material has been determined as 12.5 when set, which is comparable to that of calcium hydroxide (46) MTA's biocompatibility and low cytotoxicity, antimicrobial properties ${ }^{(47)}$ and low microleakage ${ }^{(48)}$, ability to set in the presence of blood or moisture are among the material's additional advantages ${ }^{(45)}$.

\section{CONCLUSIONS}

Within the limitation of this study:

1- Fracture strength of mature teeth is more than immature teeth.

2- Using total etch composite resin cement give more fracture strength than self etch composite resin cement.

3- Thermocycling affects negatively the fracture strength for mature or immature endodontically treated teeth.

4- No microleakage occurred irrespective to the state of restored root (mature or immature).

\section{REFERENCES}

1. Strassler HE: Restoring endodontically compromised teeth with fiber-reinforced light transmitting anchors. Contemporary Esthetics and Restorative Practice. 1999; 3(3):58-60.

2. Vichi A, Grandini S, Davidson CL \& Ferrari M (2002) An SEMevaluation of several adhesive systems used for bonding fiber posts under clinical conditions Dental Materials 18(7) 492-502.
3. Akkayan B \& Gülmez T (2002) Resistance to fracture of endodontically treated teeth restored with different post systems Journal of Prosthetic Dentistry 87(4) 431-437.

4. Idil Dikbas, Jale Tanalp, Temel Koksal1, Ays_e Yalnız, Tufan G€ung€or . Dental Traumatology 2014; 30: 49-54; doi: 10.1111/edt.12034.

5. Damle S. GL."Textbook of pediatric dentistry". Second edition. Arya Publishing House .2002, 331 - 332.

6. McComb D, Smith DC. A preliminary scanning electron microscopic study of root canals after endodontic procedures”. Journal of Endodontics. 1975, 1, 238-242.

7. Pashley DH "Smear layer: physiological considerations. Operative Dentistry Supplment.1984,3, 13-29.

8. Vichi A, Grandini S, Davidson CL, Ferrari M. "An SEM evaluation of several adhesive systems used for bonding fiber posts under clinical conditions". Dental Materials2002, 18, 495-502.

9. Sayin TC, Serper A, Cehreli ZC, Otlu HG. "The effect of EDTA, EGTA, EDTAC, and tetracycline-HCl with and without subsequent $\mathrm{NaOCl}$ treatment on the microhardness of root canal dentin". Oral Surgery, Oral Medicine, Oral Pathology, Oral Radiology, and Endodontology 2007, 104, 418-424.

10. Portell FR, Bernier WE, Lorton L, Peters DD. "The effect of immediate versus delayed dowel space preparation on the integrity of the apical seal". Journal of Endodontics.1982, $8,154-160$.

11. Fan B, Wu MK, Wesselink PR. "Coronal leakage along apical root fillings after immediate and delayed post space preparation". Endodontics and Dental Traumatology.1999, $15,124-126$.

12. Solano F, Hartwell G, Appelstein C. "Comparison of apical leakage between immediate versus delayed post space preparation using AH Plus sealer". Journal of Endodontics.2005, 31, 752-754.

13. Wu MK, Pehlivan Y, Kontakiotis EG, Wesselink PR."Microleakage along apical root fillings and cemented posts". The Journal of Prosthetic Dentistry.1998, 79, 264-269

14. Haddix JE, Mattison GD, Shulman CA, Pink FE. "Post preparation techniques and their effect on the apical seal". The Journal of Prosthetic Dentistry.1990, 64, 515-519.

15. Abramovitz L, Lev R, and Fuss Z. "The unpredictability of seal after post space preparation: a fluid transport study". Journal of Endodontics.2001, 27, 292-295. 
16. Torabinejad M, Ung B, Kettering JD. "In vitro bacterial penetration of coronally unsealed endodontically treated teeth". Journal of Endodontics.1990, 16, 566-569.

17. Khayat A, Lee SJ, Torabinejad M. "Human saliva penetration of coronally unsealed obturated root canals". Journal of Endodontics.1993, 19, 458-461.

18. Barrieshi KM, Walton RE, Johnson WT, Drake DR. "Coronal leakage of mixed anaerobic bacteria after obturation and post space preparation". Oral Surgery, Oral Medicine, Oral Pathology, Oral Radiology, and Endodontics.1997, 84,310-314.

19. Mattison GD, Delivanis PD, Thacker RW, Jr., Hassell KJ. "Effect of post preparation on the apical seal". The Journal of Prosthetic Dentistry.1984, 51, 785-789.

20. Zmener O. "Effect of dowel preparation on the apical seal of endodontically treated teeth". Journal of Endodontics. 1980, 6, 687-690.

21. Bourgeois RS, Lemon RR. "Dowel space preparation and apical leakage”. Journal of Endodontics.1981, 7, 66-69.

22. Gish SP, Drake DR, Walton RE, and Wilcox L. "Coronal leakage: bacterial penetration through obturated canals following post preparation". Journal of the American Dental Association.1994, 125, 1369-1372.

23. Raiden GC, Gendelman H."'Effect of dowel space preparation on the apical seal of root canal fillings". Endodontics and Dental Traumatology.1994, 10, 109-112.

24. Kvist T, Rydin E, Reit C. "The relative frequency of periapical lesions in teeth with root canal-retained posts". Journal of Endodontics.1989, 15, 578-580.

25. Desai $\mathrm{S}$, Chandler N. The restoration of permanent immature anterior teeth, root filled using MTA: a review. J Dent 2009; 37:652-7

26. Lawley GR, Schindler WG, Walker WA III, Kolodrubetz D. Evaluation of ultrasonically placed MTA and fracture resistance with intracanal composite resin in a model of apexification. J Endod 2004; 30:167-72.

27. Camilleri J, Gandolfi MG, Siboni F, Prati C. Dynamic sealing ability of MTA root canal sealer. Int Endod J 2011; 44:9-20.

28. Newman MP, Yaman P, Dennison J, Rafter M, Billy E (2003) Fracture resistance of endodontically treated teeth restored with composite posts. The Journal of Prosthetic Dentistry 89, 360-367

29. Sirimai S, Riis DN, Morgano SM. "An in vitro study of the fracture resistance and the incidence of vertical root fracture of pulpless teeth restored with six post-and-core systems". The Journal of Prosthetic Dentistry. 1999, 81, 262-269.

30. Pontius O, Hutter JW. "Survival rate and fracture strength of incisors restored with different post and core systems and endodontically treated incisors without coronoradicular reinforcement". Journal of Endodontics. 2002, 28, 710-715.

31. Yoshida K, Tanagawa M, Atsuta M. "In-vitro solubility of three types of resin and conventional luting cements". Journal of Oral Rehabilitation.1998, 25, 285-291.

32. Krämer N, Lohbauer U, Frankenberger R. "Adhesive luting of indirect restorations". American Journal of Dentistry.2000, 13, 60D-76D.

33. Chan FW, Harcourt JK, Brockhurst PJ. "The effect of post adaptation in the root canal on retention of posts cemented with various cements". Australian Dental Journal.1993, 38, 39-45.

34. Bitter K, Meyer-Lüeckel H, Priehn K, Kanjuparambil JP, Neumann K, Kielbassa AM.'Effects of luting agent and thermocycling on bond strengths to root canal dentine". International Endodontic Journal. 2006, 39, 809-818.

35. Knobloch LA, Kerby RE, Seghi R, Berlin JS, Lee JS. "Fracture toughness of resin-based luting cements". The Journal of Prosthetic Dentistry.2000, 83, 204-209.

36. Bailey LF, Benett RJ. Dicor surface treatments for enhanced bonding. J Dent Res 1988; 67:925-31.

37. Dental Materials. Guidance on testing of adhesion to tooth structure - ISO/TS11405:2003.

38. Guazzato M., Albakry M., Swain M M., and Ironside J." Mechanical properties of In-Ceram Alumina and In-Ceram Zirconia”. Int. J. Prosthodont. 2002, 15:183-188

39. Esquivel-Upshaw J F., Anusauic K. J, Reid M., Yang, M C K., and Lee R.B. "Fracture resistance of all-ceramic and metal ceramic inlays". Int. J. Prosthodont. 2001, 14:109-114.

40. De Melo MP, do Valle AL, Pereira JR, Bonachela WC, Pegoraro LF, Bonfante G. Evaluation of fracture resistance of endodontically treated teeth restored with prefabricated posts and composites with varying quantities of remaining coronal tooth structure. J Appl Oral Sci 2005; 13:141-6.

41. Alsamadani KH, Abdaziz el-SM, Gadel-S. Influence of different restorative techniques on the strength of endodontically treated weakened roots. Int J Dent 2012; 2012:343712.

42. Chin Nguyen: A new in vitro method for study of microleakage of dental restorative materials, DDS Vitnam. 
43. Dikbas I, Tanalp J, Koksal T, Yalnız A, Güngör T: Investigation of the effect of different prefabricated intracanal posts on fracture resistance of simulated immature teeth. 2013 Feb 4. doi: 10.1111/edt.12034.

44. Lüthy H, Loeffel O and Hammerle C H F. Effect of thermo cycling on bond strength of luting cements to zirconia ceramic. J Dent Mat. 2006; 22: 195-200.

45. Radovic I, Mazzitelli C, Chieffi N, Ferrari M. Evaluation of the adhesion of fiber posts cemented using different adhesive approaches. Eur J Oral Sci 2008; 116: 557-563.
46. Schwartz R, Mauger M, Clement D, Walker W. ineral trioxide aggregate: a new material for endodontics. J Am DentAssoc 1999; 130:967-75.

47. Torabinejad M, ong CU, Pitt Ford TR, Kettering JD. Cytotoxicity of four root-end filling materials. J Endod 1995; 21:489-92.

48. Torabinejad M, Smith PW, Kettering JD, Pitt Ford TR. Comparative investigation of marginal adaptation of mineral trioxide aggregate and other commonly used rootend filling materials. J Endod 1995; 21:295-9. 